\title{
Unmanned Aerial Vehicle classification, Applications and challenges: A Review
}

\author{
Gaurav Singhal 1, Babankumar Bansod 1* Lini Mathew 2, \\ 1 Central Scientific Instruments Organization, Chandigarh, India; gauravsinghal592@gmail.com.com \\ 2 NITTTR Chandigarh, India; leni.mathew@yahoo.com \\ * Correspondence: csiobabankumar@gmail.com; Tel.: +919888520252
}

\begin{abstract}
In past few years, unmanned aerial vehicles (UAV) or drones has been a hot topic encompassing technology, security issues, rules and regulations globally due to its remarkable advancements and uses in remote sensing and photogrammetry applications. This review paper highlights the evolution and development of UAV, classification and comparison of UAVs along with Hardware and software design challenges with diverse capabilities in civil and military applications. Further, safety and security issues with drones, existing regulations and guidelines to fly the drone, limitations and possible solutions have also been discussed.
\end{abstract}

Keywords: Drone, Remote Sensing, control station, Multispectral, Aviation, Regulations

\section{Introduction}

Technological amelioration has impacted significantly social, economic and personal life, from business approaches to international wars. These transformations can be visualized by getting benefited from these technological advancements. Unmanned aerial vehicle (UAV) also known as remotely operated aircraft is the best example to visualize the change. Unmanned Aerial vehicles do not need any pilot onboard and can be operated autonomously or remote pilot control [1,2]. UAV is an integral part of the Unmanned aerial system which incorporates UAV, communication link and ground control station. UAV overcomes the limitation of the terrestrial system in terms of accessibility, speed and reliability [3]. UAV can provide cloud-free and high-resolution images to serve the commercial applications such as agriculture, mining and monitoring. UAV was originated in defense for reconnaissance and combat purpose. Perhaps in 1916 first ever semiautomatic aero plane was developed (aerial torpedo). In 1933 Royal Navy used the drones for the gunnery practices. Later on with the advent and integration of advanced navigation sensors UAV became an integral part of armed forces. The emergence of technology not only removed the limitations of UAV exercises in the military but expanded their wings in commercial applications related to agriculture, scientific activities, recreation, servile, delivering goods, photogrammetry and many more [4].

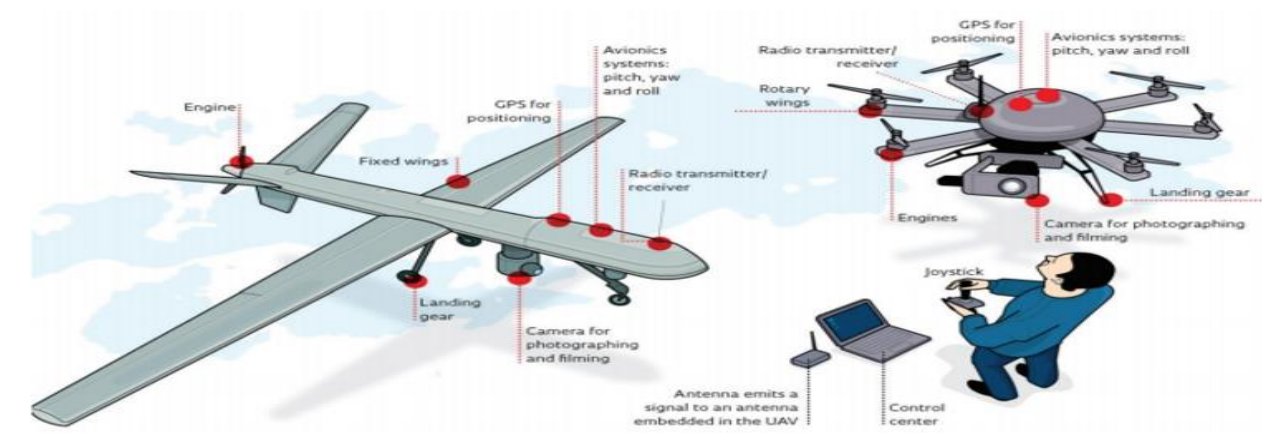

Figure 1: Fixed wing and Multirotor aerial systems [http://revistapesquisa.fapesp.br /en/2013/10/23/the-flight-of-the-falcon/] 
Agriculture and Infrastructure cover the maximum share of unmanned aerial vehicle applications. The utilisation of autonomous UAV in agribusiness is reaching out at an energetic pace in Crop health monitoring, early cautioning frameworks, forestry, fisheries, and wildlife protection[5, 6]. Onboard Narrow band visible, near-infrared and thermal sensors administer the variability of the field from nutrient mapping to crop health monitoring, so that farmer makes smart farming decisions on time. [7][8].Latest PwC report (PwC, 2016) estimated the agriculture drone market to be worth USD 32.4 billion upto 2018.

\section{Comparison of Satellite, Aircraft and UAV}

Satellite and Aircraft based technologies are the conventional methods of remote sensing which have their benefits and hindrances in the form of Coverage area, spectral, spatial and temporal resolution with onboard sensors. Along with less revisit frequency, satellite suffers from cloud cover conditions where information beneath the clouds is shadowed entirely. Aircraft systems may sustain with higher payloads and speed, but the hovering at a place and maintaining high and low speeds are the challenges [7]. Several studies were performed by various researchers to compare the three technologies such as NDVI survey of larger farmland, soil and crop mapping, Land classification. Unmanned Aerial Vehicles somehow bridges the gap of conventional technologies regarding hovering capability, maintain low and high Speed, low elevation and more importantly higher spatial and temporal resolution of images.

A comparison of satellite, aircraft and UAV is depicted in table 1.

Table 1: UAV, Airborne and Satellite System Comparison

\begin{tabular}{|c|c|c|c|c|c|}
\hline System & Resolution & $\begin{array}{c}\text { Degree of } \\
\text { Availability }\end{array}$ & $\begin{array}{l}\text { Operation } \\
\text { mode }\end{array}$ & $\begin{array}{l}\text { Payload } \\
\text { capacity }\end{array}$ & $\begin{array}{c}\text { Operating } \\
\text { cost }\end{array}$ \\
\hline UAV & $\mathrm{Cm}$ to meters & High & $\begin{array}{c}\text { Autonomous } \\
\text { or remote } \\
\text { control }\end{array}$ & Limited & Low \\
\hline Helicopters & 100 meters & High & Human Pilot & Limited & Medium \\
\hline Airborne & $\begin{array}{l}\text { Up to } 50 \\
\text { meters }\end{array}$ & Moderate & Human Pilot & $\begin{array}{l}\text { Much more } \\
\text { than } \\
\text { helicopters }\end{array}$ & High \\
\hline Satellite & $10 \mathrm{~m}-1 \mathrm{Km}$ & Poor & Autonomous & Limited & Too high \\
\hline
\end{tabular}

\section{Classification of UAV}

\subsection{Based on Aerodynamics}

A variety of UAV system has been developed and in the advancement phase, some of them includes the Fixed-wing aircraft [9-11], chopper [12, 13], multi-copter [14], motor parachute and glider [15-17], UAV with Vertical takeoff and landing [18-20], congregating ready-made parts [21] and commercialized UAV $[22,23]$.all of them are specified for a specific mission and have their zeros and ones.

Fixed wing drones are very simple but saturated in designing and manufacturing, because of successful generalisation of larger fixed-wing planes with slight modifications and improvements. Fixed wings are the main lift generating elements in response to forward accelerating speed. The velocity and steeper angle of air flowing over the fixed wings controls the lift produced. Fixed wing drones require a higher initial speed and the thrust to load ratio of less than 1 to initiate a flight [24, 25]. If fixed wing and Multirotor are compared for a same amount of payload, fixed-wing drones are more comfortable with less power requirement and thrust loading of less than 1 . Rudder, ailerons 
and elevators are used for yaw, roll and pitch angles to control the orientation of aircraft. Figure 2 shows the force applied on fixed-wing aircraft.

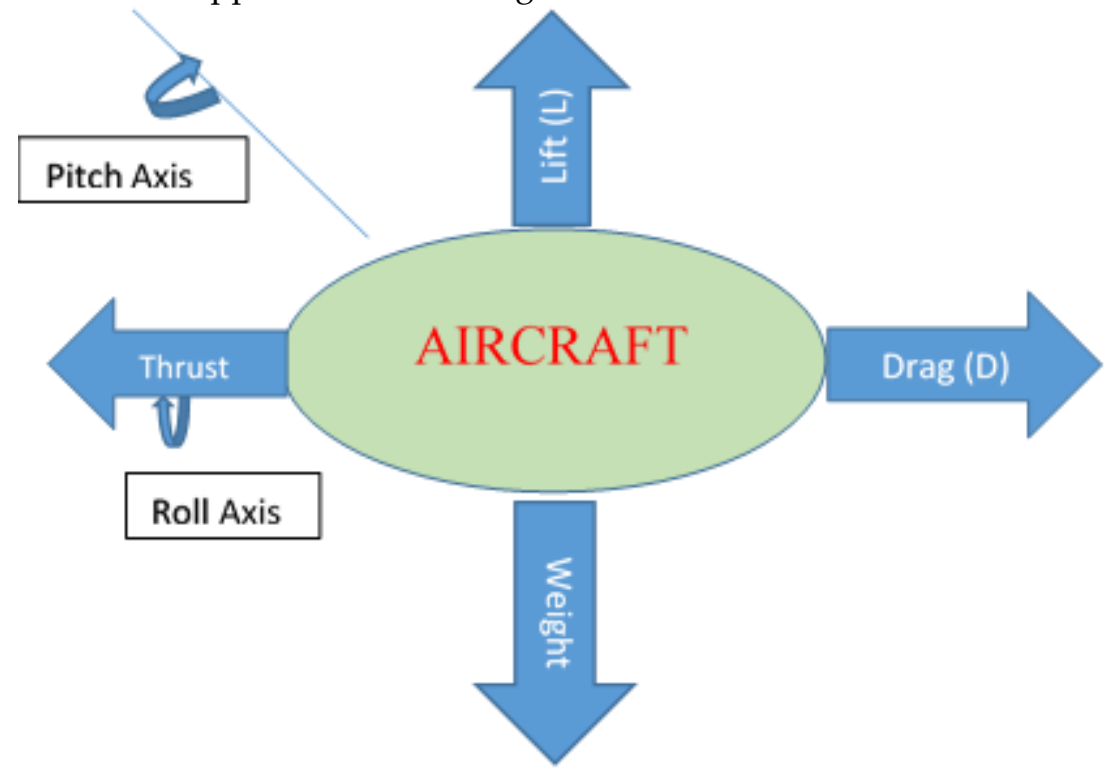

Figure 2: Fixed Wing UAV Aerodynamics

Fixed wing drones cannot hover at a place, and they cannot maintain their low speed. Subsequently, it can be seen that lift to drug ratio denotes the lift generated by a wing counter to drag generated. Fixed wing drones are more compatible with larger L/D ratio and with higher Reynolds number. Unfortunately, fixed-wing drones are less noticeable for $\mathrm{L} / \mathrm{D}<10$ for the reason that Reynolds number and efficiency decreases for smaller drones.

Flapping wing drones are primarily inspired by insects such as small hummingbirds to large dragonflies [26, 27]. The lightweight and flexible wings are inspired from the feathers of insects and birds which demonstrate the utility of weight and flexibility of wings in aerodynamics. However, these flapping wings are complex because of their complicated aerodynamics. Flapping drones can support stable flights in a windy condition, unlike fixed-wing drone. Light, flexible and flapper wings provide the flapper motion with an actuation mechanism. Intensive research on flapping wings has been carrying out by drone community and biologist because of their exclusive manoeuvrability benefits [28].

Fixed/flapping-wing: Integrated effect of the fixed and flapping mechanism is used where fixed wings are used to generate lift whereas flagging wings are used for generation of propulsion [29]. These type of drones are inspired by dragonfly which uses two pairs of wings in order to increase the lift as well as thrust forces. Hybridisation using fixed and flapping wing increases overall efficiency and aerodynamic balance [29].

Multirotor: Main rotor blade produces a forceful thrust, which is used for both lifting and propelling. Multirotor unmanned aerial vehicles are capable of vertical takeoff and Landing (VTOL) and may hover at a place unlike fixed-wing aircraft [30,31]. Multirotor are designed by number and location of motors and propellers on the frame. Their hovering capability, ability to maintain the speed makes them ideal for surveillance purpose and monitoring. The only concern with Multirotor is that they need more power consumption and makes them endurance limited. Abott equations are used for exact calculation of power and thrust requirements in multirotor aircraft.

$$
\begin{aligned}
& \text { Power }[W]=\text { Pitch } X(\text { Diameter })^{4} X(R P M)^{3} X\left(5.33 X 10^{-15}\right) \\
& \text { Thurst }[O Z]=\text { Pitch } X(\text { Diameter })^{3} X(R P M)^{2} X\left(10^{-10}\right)
\end{aligned}
$$

Multicopter is divided into specific categories based on number and positioning of motors, each category belongs to a specific type of mission[32], and based on the mission requirement they are classified in various configurations such as Monocopter, Tricopter, quadcopter, hexacopter $\left(X_{,}+\right.$ configuration) Mode, Octacopter ( $\mathrm{X},+$ configuration). 


\subsection{Based on Landing}

Horizontal takeoff and landing (HTOL) and vertical takeoff and Landing (VTOL): HTOL may be considered as the extension of fixed-wing aircraft. They have high cruise speed and a smooth landing. VTOL drones are expert in flying, landing and hovering vertically [33], but they are limited by cruise speed because of the slowing down of retreating propellers [32].

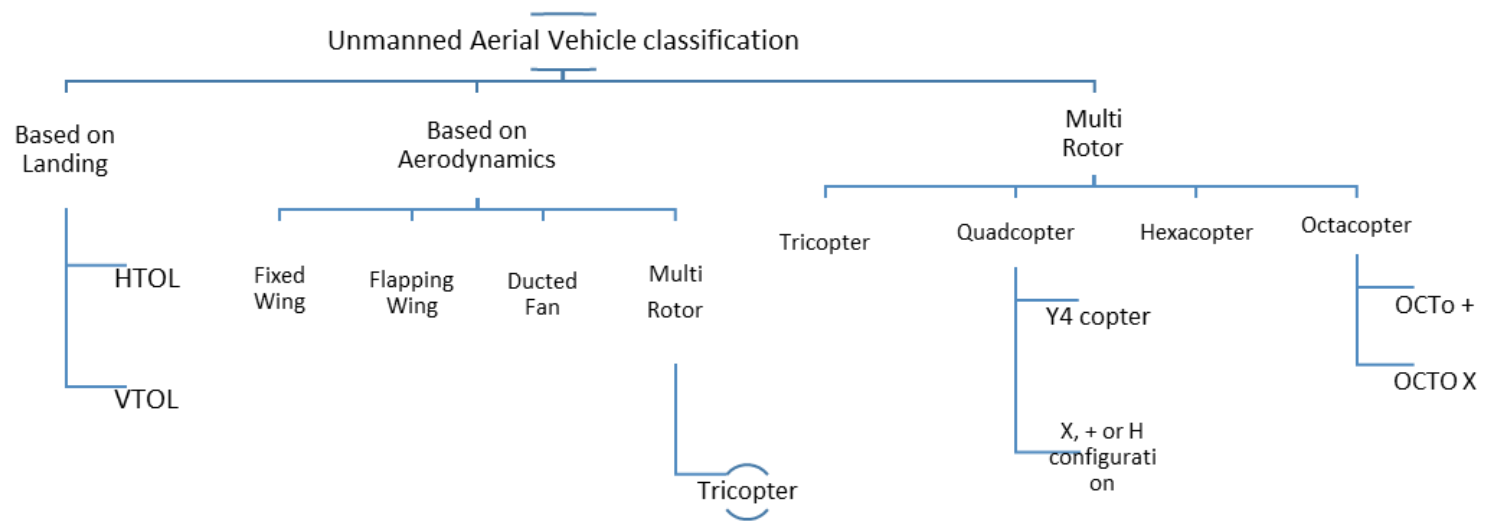

Figure 3: Classification of UAV based on Landing, Aerodynamics and weight

\subsection{Based on Weight and Range}

Some researchers and organisations have classified the drones based on weight and range. Table 2 presents the list of the unmanned aerial vehicle based on the weight and range.

Table 2: Unmanned aerial Vehicles classification based on weight and range [5, 34-36]

\begin{tabular}{llll}
\hline \hline Type & Maximum Weight & $\begin{array}{l}\text { Maximum } \\
\text { Range }\end{array}$ & Category \\
\hline Nano & $200 \mathrm{gms}$ & $5 \mathrm{Km}$ & Fixed wing, multirotor \\
Micro & $2 \mathrm{Kg}$ & $25 \mathrm{Km}$ & Fixed wing, multirotor \\
Mini & $20 \mathrm{Kg}$ & $40 \mathrm{Km}$ & Fixed wing, multirotor \\
Light & $50 \mathrm{Kg}$ & $70 \mathrm{Km}$ & Fixed wing, Multirotor \\
Small & $150 \mathrm{Kg}$ & $150 \mathrm{Km}$ & Fixed wing \\
Tactical & $600 \mathrm{Kg}$ & $150 \mathrm{~km}$ & Fixed wing \\
MALE & $1000 \mathrm{Kg}$ & $200 \mathrm{Km}$ & Fixed wing \\
HALE & $1000 \mathrm{Kg}$ & $250 \mathrm{Km}$ & Fixed wing \\
Heavy & $2000 \mathrm{Kg}$ & $1000 \mathrm{Km}$ & Fixed wing \\
Super Heavy & $2500 \mathrm{Kg}$ & $1500 \mathrm{Km}$ & Fixed wing \\
\hline \hline
\end{tabular}

Table 3: Commercial Drones Available in Global Market [37, 38]

\begin{tabular}{|c|c|c|c|c|c|}
\hline Model & Flight Mode & $\begin{array}{l}\text { Flight } \\
\text { Time }\end{array}$ & Speed & $\begin{array}{l}\text { Weight } \\
\text { (Kg) }\end{array}$ & Camera \\
\hline $\begin{array}{l}\text { Autel } \\
\text { Premium }\end{array}$ & $\begin{array}{l}\text { GPS } \cdot \text { ATTI } \\
\text { IOC }\end{array}$ & $\begin{array}{l}\text { Up to } 25 \\
\text { minutes }\end{array}$ & $35 \mathrm{mph}$ & 1.6 & $\begin{array}{l}12 \mathrm{mp} \text { Single } \\
\text { shot }\end{array}$ \\
\hline Blade BLH7480A & Bind-N-fly & $5-10$ & & $95 \mathrm{gm}$ & EFC-721 \\
\hline
\end{tabular}




\begin{tabular}{|c|c|c|c|c|c|}
\hline DJI Phantom1 & & & 22.36 & 1.2 & $4 \mathrm{~K}$ \\
\hline $\begin{array}{l}\text { DJI phantom } 3 \\
\text { professional }\end{array}$ & GPS/GLONASS & 23 & 35.7 & 1.28 & 1/2.3" CMOS \\
\hline DJI Phantom4 & & 28 & 44.7 & 1.38 & 1/2.3" CMOS \\
\hline DJI Inspire 2 & GPS & 27 & 13.42 & 3.44 & $\begin{array}{l}\text { Visible, } \\
\text { multispectral }\end{array}$ \\
\hline DJI Inspire Pro & GPS & 15 & 11.18 & 3.5 & $\begin{array}{l}\text { Visible, } \\
\text { multispectral }\end{array}$ \\
\hline $\begin{array}{l}\text { DJI } \quad \text { Matrice } \\
\text { 200/210/210 RTK }\end{array}$ & $\begin{array}{l}\text { GPS } \\
\text { (P and S mode) }\end{array}$ & 27 & 51.4 & 3.80 & $\begin{array}{l}\text { Zenmuse } \\
\text { series cameras }\end{array}$ \\
\hline KAIDENG K70C & Headless mode & 10 & --- & 0.57 & $2.0 \mathrm{MP}$ \\
\hline Parrot ANAFI & $\begin{array}{l}\text { GPS, } \\
\text { GLONASS }\end{array}$ & 25 & 34 & 0.32 & $1 / 2.4^{\prime \prime}$ CMOS \\
\hline $\begin{array}{l}\text { PARROT BEBOP } 2 \\
\text { POWER }\end{array}$ & $\begin{array}{l}\text { GPS, } \\
\text { GLONASS }\end{array}$ & 30 & --- & 0.525 & $\begin{array}{l}\text { 14-megapixel } \\
\text { CMOS }\end{array}$ \\
\hline JXD 509G & $\begin{array}{l}\text { headless } \\
\text { mode, } \\
\text { automatic } \\
\text { landing }\end{array}$ & 10 & --- & 1.2 & 2MP FPV \\
\hline Quanum Nova & GPS & 15 & --- & 0.875 & Go-pro \\
\hline SYMA X8HG & Headless mode & $7 \mathrm{~min}$ & --- & $\sim 1.5 \mathrm{~kg}$ & $\begin{array}{l}\text { 8-megapixel } \\
\text { FPV }\end{array}$ \\
\hline Yuneec Tornado & Waypoints, & 24 & 24.85 & 4.9 & $4 / 3 \quad$ Live \\
\hline H920 & Orbit Me & & & & CMOS 16MP \\
\hline TYPHOON K & GPS & 25 & 4.5 & 1.7 & $12 \mathrm{MP}$ \\
\hline TYPHOON H+ & GPS & 28 & 9 & 1.645 & 20-MP CMOS \\
\hline $\begin{array}{l}\text { WALKERA SCOUT } \\
\text { X4 }\end{array}$ & GPS & 20 & 35 & 2.27 & $\begin{array}{l}720 p \\
\text { video }\end{array}$ \\
\hline VOYAGER 3 & GPS/GLONASS & 25 & --- & 3.650 & 1080p 60FPS \\
\hline KAIDENG K70C & $\begin{array}{l}\text { Headless } \\
\text { Mode, }\end{array}$ & 10 & --- & 0.579 & 2-megapixel \\
\hline
\end{tabular}

\section{Hardware Design and Challenges}

The designing of the Unmanned aerial system includes the unmanned aerial vehicle and other subsystems which includes communication link between UAV and user, ground control station and accessories like gimbal, payload. The design of UAV itself integrates the parts evolving from vehicle frame to complete ready to fly the aerial vehicle. Selection of components like airframe, Controller, motor, propellers and the power supply is the crucial task and needs in-depth knowledge and fullfledged mathematical calculations to design a UAV for a specified mission. Figure 4 describes the subsystems and modules for the design of UAS. 


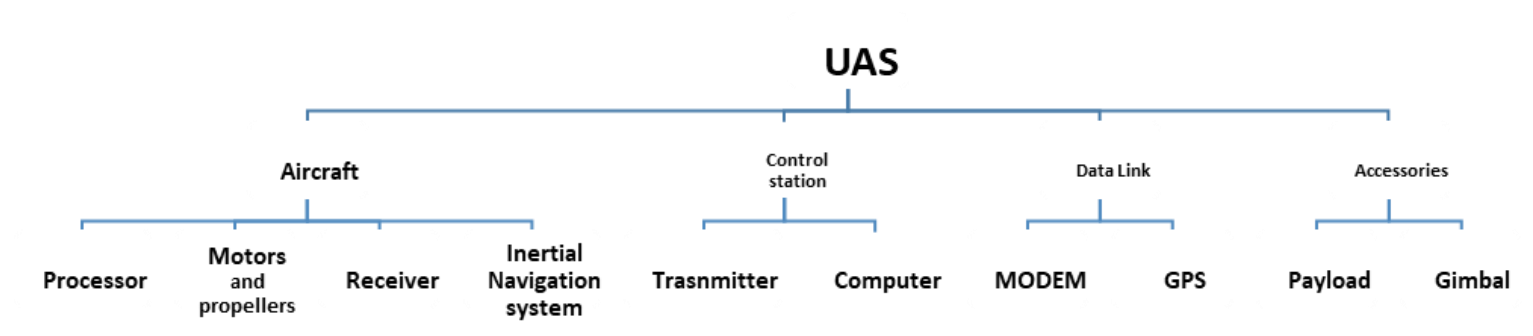

Figure 4: Unmanned Aerial System Subsystems

\subsection{Aircraft design}

The design challenges of an aircraft rely on the type of application which specifies the coverage area, maximum altitude, speed, climb rate, flight time or endurance, and stability [39]. All the specifications are prone to vary contingent on applications and the environmental effects. Higher altitude specifies a large coverage area and improves survivability although maximum altitude is limited by the aviation regulations. Climb rate also increases the survivability. Flight time is strictly dependent on the type of operation and aerodynamic design of aircraft.

The main components of aircraft subsystems are inertial measurement unit, motors, propellers and receiver, processor and an Airframe. The most common metallic materials to manufacture aircraft are alloys, aluminium and titanium, whereas nonmetallic materials include transparent and reinforced plastic [40]. Multicopter have the N brushless motors with $\mathrm{N}$ propellers. Electronic speed controller serves their purpose by varying the power supplied to motor commanded from throttle stick. They can fly in a particular direction and adjust their elevation, i.e. pitch (along $X$-axis, heading of quadcopter), roll (along Y-axis) and yaw (along Z-axis) by taking the inputs from Inertial Measurement Unit (IMU) consisting of three-axis accelerometer, gyroscope which provides 3-axis raw data and a GPS unit.

\subsection{Ground Control System}

The typical ground station consists of a wireless router along with a computer to capture, process and display of data. Typically a ground control station should fulfil requirements such as open system architecture, compatible with different platforms like airborne, ship and ground, execution of data in real time, ability to control multiple UAVs, payload control and communication with other ground control stations [41,42]. Other safety and a security function that can be expected from the ground control station include the warnings and emergency action plan in case of any failure, power outage restoration.

\subsection{Data Link}

It set up a communication channel between the Aircraft sensors and ground control station (GCS).A wireless link IEEE 802.11, is used to make a communication between aircraft central data unit and ground control station, for this purpose routers equipped with omnidirectional antennas with high gain can be used to minimise path loss and make a signal to noise ratio higher. Now a day's typical antennas work on $2.4 \mathrm{GHz}$ and minimum $12 \mathrm{dBi}$ gain. Additional wireless link based on orthogonal 
frequency division multiplexing (OFDM) is used for online video and images transmission to a ground station.

\subsection{Accessories}

With the advancement of drones, to carry out the applications such as photogrammetry, film shooting, mapping of a field, digital elevation models, monitoring and surveillance, UAV compatible cameras such as multispectral camera, thermal camera [43], hyper-spectral camera [44], digital camera [45] and film imaging units [46, 47] were used. Frequently, cameras weighing less than 12 lbs. are preferred for FPV applications, and a minimum of 12 megapixel camera is required for agriculture applications. Table 4 describes the developments in multispectral sensors for UAV.

Table 4: Common Multispectral Cameras for UAV

\begin{tabular}{|c|c|c|c|c|}
\hline Model & Spectral Bands & Resolution & Weight(gm.) & Frame Rate \\
\hline Tetracam ADC & Green(520-600nm) & $2048 \times 1536$ & 200 & --- \\
\hline Lite & $\operatorname{Red}(630-690 \mathrm{~nm})$ & pixel & & \\
\hline & $\operatorname{NIR}(760-900 \mathrm{~nm})$ & & & \\
\hline $\begin{array}{l}\text { Sentera NDVI } \\
\text { and red edge } \\
\text { sensor }\end{array}$ & Red, Red Edge and NIR & $1.2 \mathrm{Mp} \mathrm{cmos}$ & 30 & $7 \mathrm{fps}$ \\
\hline Sentera & RGB ,NIR & $\begin{array}{l}\text { CMOS } 12.3 \mathrm{Mp} \\
\text { (RGB) }\end{array}$ & 80 & $30 \mathrm{fps}$ \\
\hline $\begin{array}{l}\text { Phase One iXU } \\
1000\end{array}$ & RGB & $100 \mathrm{MP}$ & 1700 & 0.7 \\
\hline Ricoh GR2 & RGB & 16.2MP & 221 & $4 \mathrm{fps}$ \\
\hline Sentek GEMS & RGB, NIR & CMOS & 170 & $\begin{array}{l}1.4 \text { ( } 0.7 \text { seconds } \\
\text { between images) }\end{array}$ \\
\hline Hasselblad & Visible & & & \\
\hline H6D-50C & & $50 \mathrm{Mp}, \mathrm{CMOS}$ & 2115 & $30 \mathrm{fps}$ \\
\hline H6D-100c & & $100 \mathrm{Mp}, \mathrm{CMOS}$ & 2130 & $30 \mathrm{fps}$ \\
\hline GXRA16 & Visible & $16.2 \mathrm{Mp}$ & 550 & $3 \mathrm{fps}$ \\
\hline Mapir Survey 3 & RG,NIR & $12 \mathrm{MP}(\mathrm{RGB})$ & 76 & --- \\
\hline $\begin{array}{l}\text { GoPro Hero } 4 \\
\text { Silver }\end{array}$ & Visible & $12 \mathrm{MP}$ & 81.6 & 15 \\
\hline
\end{tabular}

Apart from multispectral cameras, thermal and Hyperspectral cameras are making the pace in remote sensing with drones. Drones equipped with thermal sensors are being used in mining, oil and gas industries. FLIR, telops commercial giants, have developed the thermal cameras compatible with drones. Hyperspectral sensors based remotes sensing records wavelengths with narrow spectral bands typically $5 \mathrm{~nm}$ over the visible and NIR range. Hyperspectral images provide much more information with an ultra-high resolution where entire information is inherited in each pixel in contrast to multispectral sensors. Table 5 provides information about the developments in thermal and hyperspectral cameras for UAV.

Table 5: Representative Thermal and Hyperspectral Cameras

\begin{tabular}{lllll}
\hline \hline $\begin{array}{l}\text { Manufacturer } \\
\text { and Model }\end{array}$ & Spectral Range & Resolution & Weight & Frame Rate \\
\hline
\end{tabular}




\begin{tabular}{|c|c|c|c|c|}
\hline FLIR Vue Pro & $7.5-13.5 \mu \mathrm{m}$ & $1920 \times 1080$ pixel & --- & $30 \mathrm{~Hz}$ \\
\hline FLIR Duo Pro R & $7.5-13.5 \mu \mathrm{m}$ & 336 x 256pixel & --- & $7.5 \mathrm{~Hz}$ \\
\hline $\begin{array}{l}\text { Workswell WIRIS } \\
640\end{array}$ & $7.5-13.5 \mu \mathrm{m}$ & $640 \times 512$ pixel & $390 \mathrm{~g}$ & ---- \\
\hline Zenmuse X7 & 7.5-13.5 $\mu \mathrm{m}$ & $336 \times 256$ pixel & $449 \mathrm{~g}$ & $30 \mathrm{~Hz}$ \\
\hline Pica NIR-200 & $0.9-1.7 \mu \mathrm{m}$ & $4.9 \mathrm{~nm}$ & 2700 & $520 \mathrm{fps}$ \\
\hline Hyperspectral & & & & \\
\hline $\begin{array}{l}\text { Headwell } \\
\text { Photonics }\end{array}$ & $400-1000 \mathrm{~nm}$ & InGaAs & 1025 & ---- \\
\hline Thermotenix sys. & $800-1200 \mathrm{~nm}$ & $\begin{array}{l}\text { Silicom } \\
\text { ampohorous }\end{array}$ & 105 & ---- \\
\hline Telops MSM2K & $1.5-5.5 \mu \mathrm{m}$ & $320 X 256$ pixel & --- & $90000 \mathrm{~Hz}$ \\
\hline MS M100k & $3-4.9 \mu \mathrm{m}$ & $640 \times 512$ pixel & --- & $120000 \mathrm{~Hz}$ \\
\hline MS M350 & $1.5-5.4 \mu \mathrm{m}$ & $640 \times 512$ pixel & --- & $4980 \mathrm{~Hz}$ \\
\hline
\end{tabular}

\section{Data collection and analysis}

The growing popularity with endless possibilities of drones drive us to figure out the methods to data collection and analysis to utilize them with leveraged potential. Since collection and processing of UAV data is a long process, involving data collection, pre-processing of images, classification of images for features extraction, calculation of mathematical equations based on reflectances such as Indices and then the creation of a suitable model for results visualisation and interpretation. This section of the paper describes each step and makes a comparison of software's dedicated for UAV data collection and processing.

Data collection step involves the flight planning, marking Ground control points (GCPs) for samples collected and the UAV flight itself. Correct Pre-processing with a needful accuracy of UAV data is the key step for the development of models because lack of pre-processing will distort the following processes and will generate the wrong outcomes. Pre-processing of UAV data includes the images selection, accurate georeferencing and ortho-rectification and mosaicking, (aligning images using Image control points, point cloud and GCPs). Classification of georeferenced UAV images includes the supervised and unsupervised techniques for planimetric features extraction like road, railway track, agriculture land, forest, land cover and water bodies. Maximum likelihood classification (MLC), random forest and Support vector machine (SVM) are the examples of relevant classifiers. Manual classification can be tried in case of unsatisfactory results. The next step is dependent on the case study, basically this type of processing is tried for Land use land cover classification, Agriculture biophysical parameters determination and soil study. Some of the popular Indices are Normalized difference vegetation Index (NDVI), Green-Red Vegetation Index (GRVI), Soil Adjusted Vegetation Index (SAVI) and Modified Chlorophyll Index (MCI). The last step is the creation of models for a specific case study. 


\subsection{UAV Data Processing Software}

UAV software simplifies the flight planning, processing and analysis of UAV data to provide actionable intelligence to service providers and farmers so that inputs can be optimised and better decisions can be made with reduced cost. Besides agriculture, these software are often utilised in mining, construction, surveillance, rescue operation and recreational purpose also. A good UAV software at least must include the automation of UAV flight plans, augmented view, Geo-rectification of images and 2D/3D models generation. Table 6 creates a comparison chart of various UAV software with their pros and cons.

Table 6: UAV data processing software comparison

\begin{tabular}{|c|c|c|c|}
\hline Software & Known for & Pros & Cons \\
\hline Aero Points & $\begin{array}{l}\text { AeroPoints provides } \\
\text { accurate ground control } \\
\text { points (GCP) for UAV } \\
\text { survey. }\end{array}$ & $\begin{array}{l}\text { Automatics Data } \\
\text { Upload, fast and easy } \\
\text { to setup }\end{array}$ & $\begin{array}{l}\text { Lack in functions like } \\
\text { NDVI maps, 3D models } \\
\text { creation }\end{array}$ \\
\hline Agisoft & $\begin{array}{l}\text { Generation of 3D models } \\
\text { and photogrammetric } \\
\text { processing }\end{array}$ & $\begin{array}{l}\text { Cost-effective all-in- } \\
\text { one software suite } \\
\text { with a full range of } \\
\text { image sensors } \\
\text { including NIR, RGB, } \\
\text { thermal and multi- } \\
\text { spectral. }\end{array}$ & $\begin{array}{l}\text { Compare to Pix } 4 \text { d it is } \\
\text { clunky and with less } \\
\text { functionality. One license } \\
\text { for one computer only. }\end{array}$ \\
\hline Drone Deploy & $\begin{array}{l}\text { Create accurate, high- } \\
\text { resolution maps, reports, } \\
\text { and 3D models, as well as } \\
\text { real-time 2D Live Maps } \\
\text { for immediate analysis. }\end{array}$ & $\begin{array}{l}\text { more suited to } \\
\text { agricultural } \\
\text { applications and } \\
\text { compatible with } \\
\text { third-party UAV } \\
\text { hardware and } \\
\text { accessories }\end{array}$ & $\begin{array}{l}\text { Surface detail for } \\
\text { buildings is somewhat } \\
\text { disappointing compared } \\
\text { to the more specialised } \\
\text { solutions from Agisoft } \\
\text { and Pix4D. }\end{array}$ \\
\hline Drone & Import your flight log to & Compliance \& & Not capable to make \\
\hline Logbook & $\begin{array}{l}\text { fill info automatically, } \\
\text { view GPS trace and } \\
\text { replay it in 3D. }\end{array}$ & $\begin{array}{l}\text { Custom Reporting, } \\
\text { Mission Planning \& } \\
\text { Operations Calendar }\end{array}$ & $\begin{array}{l}\text { Digital elevation and } \\
\text { digital terrain models }\end{array}$ \\
\hline $\begin{array}{l}\text { DroneMapper } \\
\text { Rapid }\end{array}$ & $\begin{array}{l}\text { Orthomosaicking, DEM, } \\
\text { Robust processing } \\
\text { Algorithm }\end{array}$ & $\begin{array}{l}\text { Freely available for } \\
\text { download and testing } \\
\text { on limited data set }\end{array}$ & $\begin{array}{l}\text { Limited to processing of } \\
150 \text { images for a scene }\end{array}$ \\
\hline $\begin{array}{l}\text { DroneMapper } \\
\text { Rapid Expert }\end{array}$ & $\begin{array}{l}\text { Full photogrammetric } \\
\text { functionality and allows } \\
\text { input of up to } 1000 \text { geo- }\end{array}$ & $\begin{array}{l}\text { Can be used upto } \\
1000 \text { georectified } \\
\text { images and can }\end{array}$ & $\begin{array}{l}\text { Does not have self- } \\
\text { calibration facility }\end{array}$ \\
\hline
\end{tabular}


tagged JPEG images of 12 produce $\mathrm{X} 8, \mathrm{X} 4$ or $\mathrm{X} 2$

Mpixel format or greater. DEM

Field Agent

Replacement of sentera's

AgVault, allows you to

scout your crops,

capturing health and

vegetation index data in

near real time

Live NDVI

Video technology-

livestream NDVI video at the field's edge

Pospac UAV

Direct georeferencing and post processing software

Pix4D

Photo Mod

Sensefly

eMotion

Sense fly

Survey 360

Ugcs

Plans UAV flight, Creates

orthomosaics, point

clouds and professional

3D models

Provides all

photogrammetric

products like DEM,

dDSM, 2D and 3D-

vectors, orthomosaics

Drone flight planning and

data management

Complete aerial mapping system

3D mission planning environment, plan and fly mission without internet connection
IOS Mobile device

enabled automated

flight with unlimited

NDVI images

Provides NDVI video

in real time while

drone is still in air

Maximum accuracy

and efficiency with

compatible drone

Photo camera Self

Calibration,

automatic DTM

generation

high performance,

simplified user-

friendly interface and

automation of

photogrammetric

operations

Connects wirelessly

to your drones, finger

swipe flight planning

and full 3D

environment,

Multiflight mission

support

Limited functionality for

mobile free version, and

$29 \$$ per month for full

functionality

Compatible only with

Sentera Double $4 \mathrm{~K}$ sensor

Compatible with APX-15

L-UAV

Topographic maps can be created only manually.

Does not have the camera self- calibration facility unlike pix4D

Very advanced software but no real time NDVI processing.

Does not provide fully 3D environment

provides accurate

point cloud and

surface model

outputs in lesser time enables supports for the majority of drones, creates routes No real time NDVI video, need of graphics card with DirectX 9 support in no-fly zones for major airports 


$\begin{array}{llll}\text { Virtual } & \text { 3D Visualization } & \text { Flood simulation } & \text { Virtual Surveyor is not } \\ \text { Surveyor } & \text { Photogrammetry, Virtual } & \text { capability, fast } & \text { responsible for reliability, } \\ & \text { Surveying, flight } & \text { simulation and } & \text { accuracy and suitability } \\ \text { planning and civil } & \text { interoperable with } & \text { of information. } \\ \text { designing } & \text { Computer Aided } \\ & \text { Design environment, } \\ & \text { can process huge } \\ & \text { amount of data files }\end{array}$

\section{Applications}

Since Drones provide supremacy over conventional remote sensing technologies and their benefits lie in terms of less power consumption, less risk to human life, ease to data collection, hovering, and ultra-high spatial resolution forges them an excellent choice for surveying and mapping. Following pioneer, studies demonstrate the relevance and uniqueness of drones in the civil, logistics, agriculture and Defense sectors. Figure 5 depicts the potential applications of UAV in civil, environment and defence sectors.

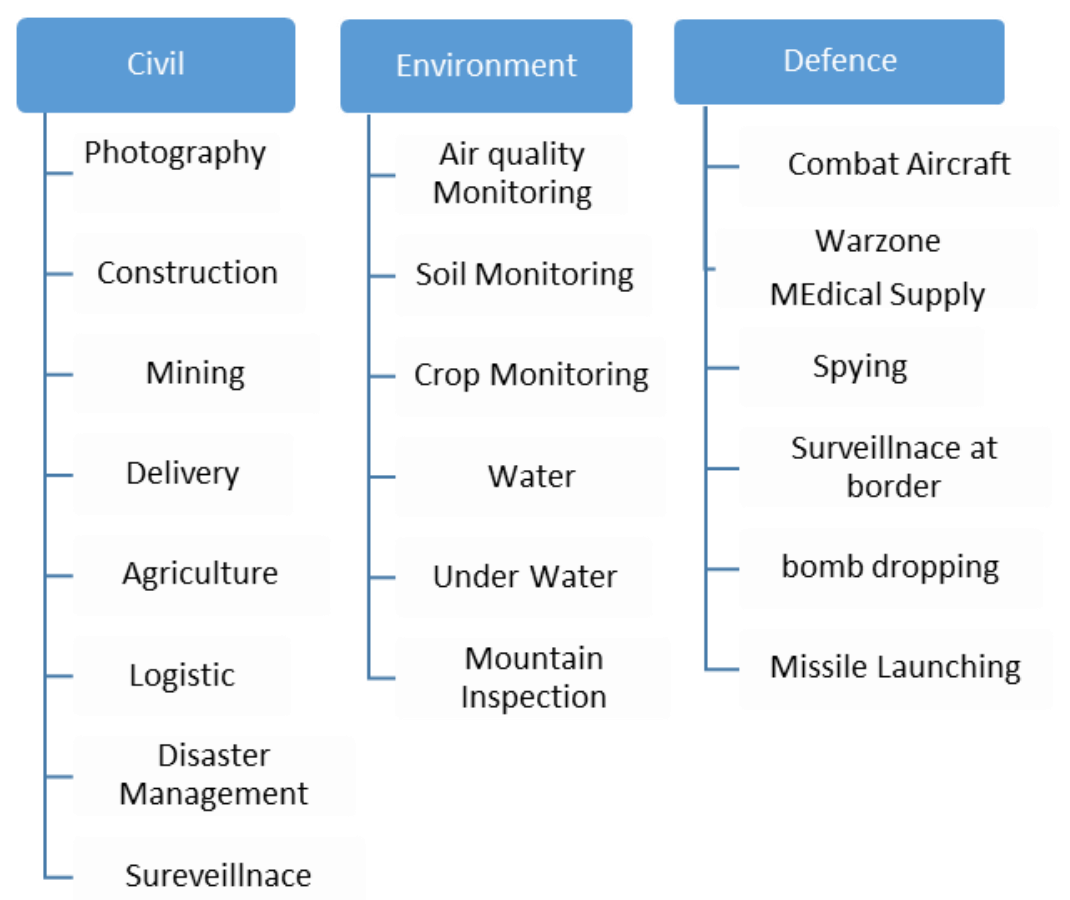

Figure 5: Potential Applications of Drones 


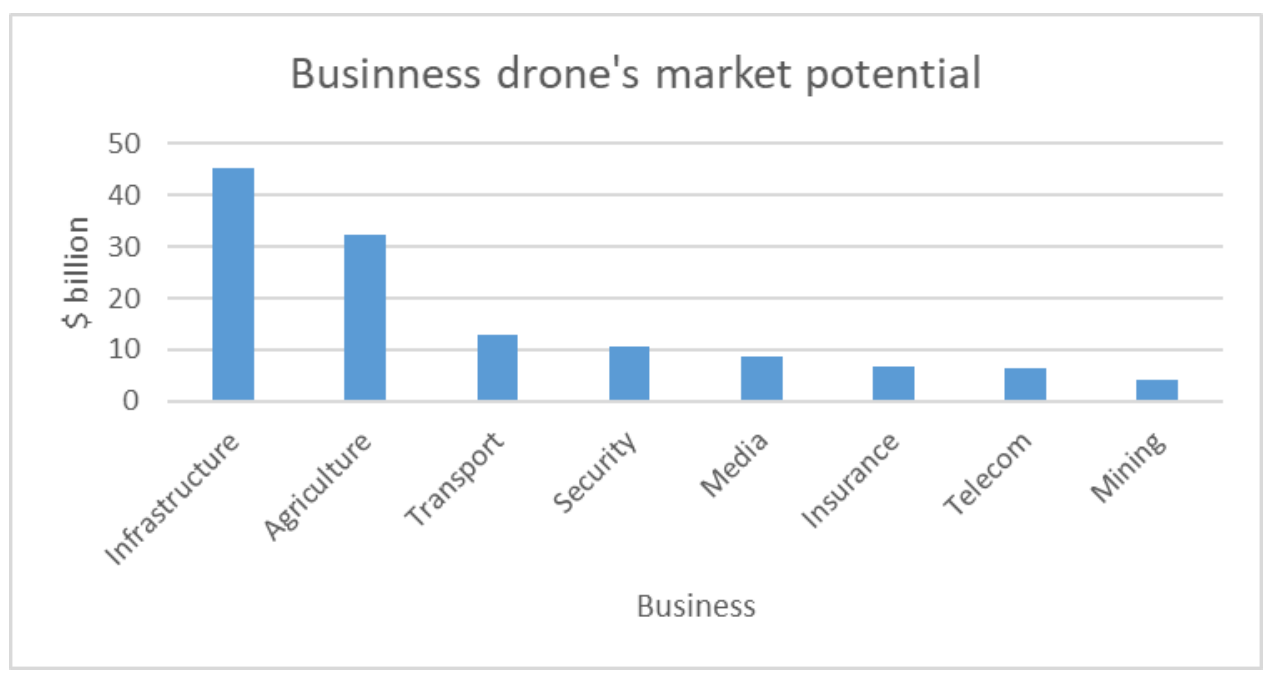

Figure 6: Market Potential of Drones

\subsection{Drones in Agriculture}

The sole aim of precision agriculture is to apply optimum amount of input at the right time and place to make better products. Common practices of precision farming are the data collection and variability mapping of agriculture lands, data analysis, making farming management decision based on results inferred from analysis and finally controlled application such as pesticide spraying and fertilisers. Agriculture has widely adopted the art of remote sensing using traditional satellite and aerial platforms. The capacity of a satellite to monitor map the vegetation is built upon the spatial, temporal and spectral resolution of sensors onboard such as MODIS, OLI, and AVHRR [48-52]. In 2013, the launch of Operational Land Imager (OLI) on-board Landsat 8 with a temporal resolution of $30 \mathrm{~m}$ provided images with a spatial resolution of 30 meters and 15 meters for panchromatic in 11 bands ranging from $435 \mathrm{~nm}$ to $12510 \mathrm{~nm}$. [53, 54]. A considerable amount of research work has been carried out in the area of precision farming using satellite-based remote sensing, and the results are auspicious. Research work including wheat yield variation due to climate variation[55], mapping of irrigated areas using AVHRR time series analysis [56], estimation of crop yield[57-59], Crop water stress management [60, 61], forest cover classification and monitoring [62] has impacted Indian and global agriculture in terms of productivity analysis and farming management. However, this technique is somewhat limited to coarse resolution and cloud cover, Later on, UAS introduced the cheaper and low altitude alternative to providing high-resolution images.

[63] Used a Microdrone MD4-200 with a team ADC lite digital CMOS camera with image resolution of 1200x1024 pixels to estimate nitrogen and aboveground biomass of soybeans, alfalfa and corn crops. [64] captured the images of agriculture land using helicopter based unmanned aerial vehicle in a thermal band with $40 \mathrm{~nm}$ resolution and $400-800 \mathrm{~nm}$ spectral range with $20 \mathrm{~nm}$ resolution using onboard Thermal and multispectral camera to target the biophysical parameters. [65] Used a drone along with multispectral and thermal sensors to delineate the spatial variability of water within a commercial rain-sustained vineyard.

\subsection{Drones in Forestry, fisheries and wildlife protection}

Drone bridges the gap of satellite imagery of less availability and cloud cover by performing Various tasks like measuring canopy height, tracking of forest wildlife's, support in forest management, forest fires detection and control, survey forests and mapping canopy gaps easily. [66] Targeted forest fire detection and monitoring using remotely controlled fixed wing UAV onboard thermal and hyperspectral sensors. Animal poaching and adverse climate conditions have a destructive impact on wildlife. UAV equipped with thermal sensors [67] along with satellite are being approached for 
monitoring, tagging and counting of animals which help to curb the poaching of animals and conserve the wildlife.

\subsection{Drones in defence}

The advent of UAV was started initially with the aim of transacting the war missions like intelligence, spying, reconnaissance vigilance and target detection; later they were introduced for civil and logistic applications [68]. USA, UK, Russia, India and Israel are the leading countries in the development and deployment of military drones. In 2017 the acceleration in the proliferation of military along with civilian drones was observed, and a maximum number of drone strikes by USA and UK were noted. Breakthrough research and remarkable advancements in the area of swarming drones, jet-powered and Microdrones. According to the Bureau of Investigative Journalism, the US launched more than two times more strikes in 2017 than the year 2016. Following the bar chart shows the data of US strikes on Somalia, Yemen and Afghanistan from the year 2014-2017[69].

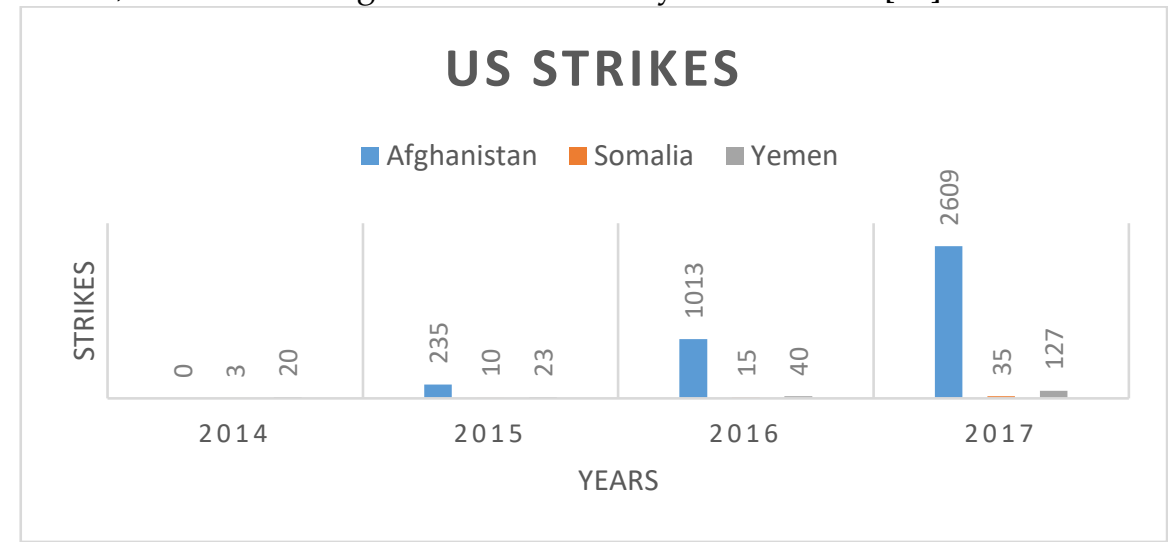

Figure 7 Number of drone strikes carried out by the USA

India recently has developed DRDO Lakshya, DRDO Aura, DRDO Rustom a Medium-Altitude Long-Endurance (MALE) system being used for target acquisition, releasing missiles, bomb dropping and combat missions [70].

\subsection{Drones for civil applications}

Drones are being fascinated in all commercial stratums from electricity companies to the railway industry. Electrical companies are preferring drones for inspection of high tension lines with ease of risky task of climbs and power outages[71, 72]. Railway companies have employed drones for monitoring and inspecting the track faults in constrained access areas. The Indian government is planning $3 \mathrm{~d}$ mapping of thousands of kilometres long railway corridors and national highways. Amazon inspired from margarita pizza delivery with drones, tested the parcel delivery with drones although commercialisation of this project is awaited. Drones are helpful in performing search and locate operations of missing people during calamities condition. A trial to locate people in Donegal mountain range, Ireland and rescue operation of 200 people in flood zone by Chennai police, India exemplifies the potential and necessity of drones. Medical facility delivery using drones performed in many countries like the USA. Electricity generation through high elevation and high-speed drones is another exploratory area.

\section{Challenges}

\subsection{Technological gaps}


There is always a tradeoff between Payload capacity and flight time in drone technology. Conventionally, onboard lightweight lithium-ion batteries are used to supply power to UAV, but their power backup is not comparable with other batteries. With the increase in payload, endurance decreases and hence mission may not get its completion. Fixed wing drones are efficient in power usage, but they have the drawback of hovering and speed control. Flying a single drone may also encounter a flight failure due to some technological and climatic reasons, so there is always a need to provide backup. Upcoming swarm flight of drones can execute this task, where in case of failure of one drone, others complete the mission. This technology is dependent on Swarm motion of insects, ants and birds and makes use of artificial intelligence, yet in developing phase.

Drones are still limited by controlling through human operators, integration of Artificial Intelligence will allow a drone to make smart decisions and operate accordingly instead of human controllers. Possible gains and harms are yet to be explored in this direction[73, 74].

Drones also suffer from windy conditions and adverse climate changes. Spraying Drones are efficient to spray less area, but for mass spraying, they become less efficient, and the operation cost becomes high.

Another concern is too technical learning of garners to make use of drone-based precision farming and to make the drone-based system fully automatic from image acquisition to making complex statistical models and decision support system. A GPS mounted on drone connects with four satellites to detect the position, velocity and elevation accurately. Since GPS signals are very much prone to noise and interference, there is a finite possibility of losing contact. At that time it is recommended that instead of emergency landing, their location should be estimated. The inertial navigation system combined with GPS provide a solution for this situation. Efficient algorithms have to be designed and tested to estimate the position and elevation correctly.

Besides the drone hardware design challenges, the cameras used for precision agriculture applications also puts some limitations.

The multispectral images collection is very much prone to get affected by total irradiation along with sun angle and adverse weather conditions such as rain, heavy wind. Comparison of UAV data and satellite data puts two significant limitations that data has to be resampled to make equal spatial resolution images and secondly, if there is a cloud cover then it is almost impossible to compare the images since the information beneath the ground gets shadowed.

Onboard thermal sensors can detect the water utilisation of plants based on radiated temperature. The temperature variations in plants are exiguous which makes it difficult to discriminate other factors which may affect plant water such as sun irradiation. So further research is required.

\subsection{Safety, Privacy and Security Issues}

Some life-threatening issues because of rapid use of drones uncovered the concerns and challenges towards safety and security. Airworthiness, malicious practices and interference to public property are the primary concerns of safety, which puts a significant question mark on use of drone since modern approaches to resolve these issues are not up to the mark and does not give guarantee for the safe use of a drone. Air traffic control needs to be installed and monitored to ensure the inference avoidance in the airspace.

Table 7: State of the art and Proposed solutions to UAV challenges [75, 76]

\begin{tabular}{llll}
\hline \hline Challenges & Concern & $\begin{array}{l}\text { The present state of Proposed Solution } \\
\text { the art }\end{array}$ \\
\hline $\begin{array}{l}\text { Technological } \\
\text { challenges }\end{array}$ & Payload & and & $\begin{array}{l}\text { The tradeoff between Design Standards } \\
\text { payload and flight Improvement } \\
\text { time }\end{array}$ \\
& & &
\end{tabular}




\begin{tabular}{|c|c|c|c|}
\hline Safety and security & $\begin{array}{l}\text { Malicious practices } \\
\text { and interference to } \\
\text { private and public } \\
\text { freedom }\end{array}$ & $\begin{array}{l}\text { Certification and } \\
\text { guidelines but not } \\
\text { explicitly mentioned } \\
\text { (if yes they are in } \\
\text { drafted form) }\end{array}$ & $\begin{array}{l}\text { Allocation of the } \\
\text { Unique identification } \\
\text { number(UIN) } \\
\text { License for owners } \\
\text { and flyers }\end{array}$ \\
\hline Aviation interference & $\begin{array}{l}\text { Breaching commercial } \\
\text { and restricted airspace }\end{array}$ & $\begin{array}{l}\text { The user must keep the } \\
\text { drone in Sight }\end{array}$ & $\begin{array}{l}\text { Use of onboard GPS } \\
\text { and Jammer }\end{array}$ \\
\hline Liability & $\begin{array}{l}\text { Public or private } \\
\text { damage }\end{array}$ & No clear guidelines & $\begin{array}{l}\text { Governing bodies } \\
\text { should create laws } \\
\text { and guidelines }\end{array}$ \\
\hline $\begin{array}{l}\text { Government rules and } \\
\text { regulations }\end{array}$ & $\begin{array}{l}\text { Confined regulatory } \\
\text { frameworks, } \\
\text { insufficiency of } \\
\text { international } \\
\text { standards }\end{array}$ & $\begin{array}{l}\text { Heterogeneous, } \\
\text { discordant regulations } \\
\text { and conflict between } \\
\text { regulations and } \\
\text { technology }\end{array}$ & $\begin{array}{l}\text { Creation of Air traffic } \\
\text { control board for } \\
\text { drones, } \\
\text { Balancing regulations }\end{array}$ \\
\hline Privacy & $\begin{array}{l}\text { Exposure to public } \\
\text { and private property }\end{array}$ & Legal actions are taken & $\begin{array}{l}\text { Proper guidelines and } \\
\text { regulations }\end{array}$ \\
\hline
\end{tabular}

\subsection{Controlling bodies and Regulations}

Since long, UAV has been used for military purpose but the bans, inadequate rules and shortcomings interrupted the universal acceptance of UAV. The advancement and accelerated use of UAV in commercial applications demands for regulation challenges in order to ensure the safe, secure and authenticated use. [77]. International Regulatory bodies like the International Civil Aviation Organization (ICAO) and European Aviation Safety Agency (EASA) invites states and organizations to frame policies and standards for civil aviation enterprise [78]. Several countries are making efforts in this direction and have proposed regulations [79], some of them are being discussed in the following section.

Australian Civil aviation safety authority revised the unmanned aircraft regulations in 2016 and included the new rules for remotely piloted aircraft. A pilot license and certificate is required for remote operation of UAV weighing greater than $2 \mathrm{~kg}$. The certification covers many aspects including pilot information, maintenance, liability and safety aspects. Similarly, German air traffic act imposes rules and demands authorisation from aviation authority for an unmanned aerial vehicle weighing more than 5 kilograms and not being used for recreational purposes. Authorisation ensures the privacy, public safety and information protection. Unmanned aerial vehicles weighing more than 25 kilograms are restricted to take a fly beyond visual line of sight. France recently imposed two regulations for the use of civilian UAV. These regulations classified the UAV into three classes creational, experimental purpose and particular activities drone. Drone authorisation, altitude limits, weight and performance limits are mentioned in the regulations. France aviation laws also restrict the movement of the drone geographically such as in military peripheries, historic monuments, national parks and nature reserves. In India, Director General of Civil Aviation (DGCA), Department of Civil Aviation drafts and regulates the policies for remotely piloted aircraft. A Unique Identification Number along with UAV operator Permit is required to fly drones, with proper adherence of guidelines such as prohibition to restricted areas such as Eco-Sensitive areas, beyond $500 \mathrm{~m}$ into the sea from the coastline and beyond $25 \mathrm{~km}$ from international border [80, 81]. Israel civil aviation authority regulates the laws regarding manufacturing, training and operations included the flight elevation, regulated and recognised routes and communication devices in Israel and enforced 
these rules to all instructors, operators and manufacturers. Violation of licensing rules imposes the same penalties as applicable to manned aircraft. The United States Federal Aviation Administration (FAA) integrated the unmanned aerial system in the National Airspace system with the conditions of not compromising with safety, security and capacity.

\section{Conclusion}

The future generation is dependent on drones; they will create a new market. Drones are being upgraded and adopted by almost all commercial markets including precision agriculture, logistics and infrastructures. Future technology focused on increasing endurance, payload, improvement in the interaction between human and UAV and making clear rules and regulations for the safe and secure operation of UAV. Besides this, Integration of Artificial intelligence with drone technology will enable the drone to take decisions and independence to human controllers.

Conflicts of Interest: The authors declare no conflict of interest.

\section{References}

[1] S. G. Gupta, M. M. Ghonge, and P. Jawandhiya, "Review of unmanned aircraft system (UAS)," International Journal of Advanced Research in Computer Engineering \& Technology (IJARCET), vol. 2, pp. pp: 1646-1658, 2013.

[2] I. s. c. AN/190. unmanned Aircraft system [Online]. Available: www.icao.int/Meetings/UAS/Documents/Circular\%20328_en.pdf

[3] B. P. Tice, "Unmanned aerial vehicles: The force multiplier of the 1990s," Airpower Journal, vol. 5, pp. 41$54,1991$.

[4] U. E. Franke, "Civilian drones: Fixing an image problem?" ISN Blog. International Relations and Security Network. Retrieved, vol. 5, 2015.

[5] A. C. Watts, V. G. Ambrosia, and E. A. Hinkley, "Unmanned aircraft systems in remote sensing and scientific research: Classification and considerations of use," Remote Sensing, vol. 4, pp. 1671-1692, 2012.

[6] T. Zajkowski, "Unmanned aerial vehicles: Remote sensing technology for the USDA Forest Service," Rem. Sens Applications Center, Salt Lake City, 2003.

[7] B. Bansod, R. Singh, R. Thakur, and G. Singhal, "A comparison between satellite based and drone based remote sensing technology to achieve sustainable development: a review," Journal of Agriculture and Environment for International Development (JAEID), vol. 111, pp. 383-407, 2017.

[8] G. M. Crutsinger, J. Short, and R. Sollenberger, "The future of UAVs in ecology: an insider perspective from the Silicon Valley drone industry," ed: NRC Research Press, 2016.

[9] R. W. Beard, D. Kingston, M. Quigley, D. Snyder, R. Christiansen, W. Johnson, et al., "Autonomous vehicle technologies for small fixed-wing UAVs," Journal of Aerospace Computing, Information, and Communication, vol. 2, pp. 92-108, 2005.

[10] J. Everaerts, "The use of unmanned aerial vehicles (UAVs) for remote sensing and mapping," The International Archives of the Photogrammetry, Remote Sensing and Spatial Information Sciences, vol. 37, pp. 1187-1192, 2008.

[11] D. Kingston, R. Beard, T. McLain, M. Larsen, and W. Ren, "Autonomous vehicle technologies for small fixed wing UAVs," in 2nd AIAA" Unmanned Unlimited" Conf. and Workshop \& Exhibit, 2003, p. 6559.

[12] E. Ben-Dor, "Quantitative remote sensing of soil properties," 2002.

[13] C. Sebastian, F. Remondino, M. De Giglio, M. Dubbini, M. Gattelli, A. Lucieer, et al., "Article Evaluating Multispectral Images and Vegetation Indices for Precision Farming Applications from UAV Images."

[14] R. Ehsani, S. Sankaran, J. Maja, and J. C. Neto, "Affordable multirotor Remote sensing platform for applications in precision horticulture," in the International Conference on Precision Agriculture, 2014.

[15] R. Bryant, M. S. Moran, S. A. McElroy, C. Holifield, K. J. Thome, T. Miura, et al., "Data continuity of Earth Observing 1 (EO-1) Advanced Land I satellite imager (ALI) and Landsat TM and ETM+," IEEE transactions on geoscience and remote sensing, vol. 41, pp. 1204-1214, 2003.

[16] C. C. Lelong, P. Burger, G. Jubelin, B. Roux, S. Labbé, and F. Baret, "Assessment of unmanned aerial vehicles imagery for quantitative monitoring of wheat crop in small plots," Sensors, vol. 8, pp. 3557-3585, 2008.

[17] R. C. B. Sampaio, A. C. Hernandes, M. Becker, F. M. Catalano, F. Zanini, J. L. Nobrega, et al., "Novel hybrid electric motor glider-quadrotor MAV for in-flight/V-STOL launching," in Aerospace conference, 2014 IEEE, 2014, pp. 1-12. 
[18] U. Ozdemir, Y. O. Aktas, A. Vuruskan, Y. Dereli, A. F. Tarhan, K. Demirbag, et al., "Design of a commercial hybrid VTOL UAV system," Journal of Intelligent \& Robotic Systems, vol. 74, pp. 371-393, 2014.

[19] J. Primicerio, S. F. Di Gennaro, E. Fiorillo, L. Genesio, E. Lugato, A. Matese, et al., "A flexible unmanned aerial vehicle for precision agriculture," Precision Agriculture, vol. 13, pp. 517-523, 2012.

[20] P. Spanoudakis, L. Doitsidis, N. Tsourveloudis, and K. Valavanis, "Vertical TakeOff and Landing vehicle market overview," KOREA, vol. 1, 2003.

[21] Y. Huang, S. J. Thomson, W. C. Hoffmann, Y. Lan, and B. K. Fritz, "Development and prospect of unmanned aerial vehicle technologies for agricultural production management," International Journal of Agricultural and Biological Engineering, vol. 6, pp. 1-10, 2013.

[22] K. M. Fornace, C. J. Drakeley, T. William, F. Espino, and J. Cox, "Mapping infectious disease landscapes: unmanned aerial vehicles and epidemiology," Trends in parasitology, vol. 30, pp. 514-519, 2014.

[23] H. Kutnjak, J. Leto, M. Vranić, K. Bošnjak, and G. Perčulija, "Potential of aerial robotics in crop production: high resolution NIR/VIS imagery obtained by automated unmanned aerial vehicle (UAV) in estimation of botanical composition of alfalfa-grass mixture," in 50th Croatian and 10th International Symposium on Agriculture, 2015.

[24] M. Hassanalian and A. Abdelkefi, "Design, manufacturing, and flight testing of a fixed wing micro air vehicle with Zimmerman planform," Meccanica, vol. 52, pp. 1265-1282, 2017.

[25] T. J. Mueller, "Aerodynamic measurements at low Reynolds numbers for fixed wing micro-air vehicles," NOTRE DAME UNIV IN DEPT OF AEROSPACE AND MECHANICAL ENGINEERING2000.

[26] M. A. Fenelon and T. Furukawa, "Design of an active flapping wing mechanism and a micro aerial vehicle using a rotary actuator," Mechanism and Machine Theory, vol. 45, pp. 137-146, 2010.

[27] W. Shyy, Y. Lian, J. Tang, D. Viieru, and H. Liu, Aerodynamics of low Reynolds number flyers vol. 22: Cambridge University Press, 2007.

[28] W. Shyy, H. Aono, C.-k. Kang, and H. Liu, An introduction to flapping wing aerodynamics vol. 37: Cambridge University Press, 2013.

[29] K. Jones, C. Bradshaw, J. Papadopoulos, and M. Platzer, "Bio-inspired design of flapping-wing micro air vehicles," The Aeronautical Journal, vol. 109, pp. 385-393, 2005.

[30] P. M. Joshi, "wing analysis of a flapping wing Unmanned aerial vehicle using CFD," Development, vol. 2, 2015.

[31] K. Schauwecker, N. R. Ke, S. A. Scherer, and A. Zell, "Markerless visual control of a quad-rotor micro aerial vehicle by means of on-board stereo processing," in Autonomous Mobile Systems 2012, ed: Springer, 2012, pp. 11-20.

[32] R. Austin, Unmanned aircraft systems: UAVS design, development and deployment vol. 54: John Wiley \& Sons, 2011.

[33] M. Hassanalian and A. Abdelkefi, "Classifications, applications, and design challenges of drones: a review," Progress in Aerospace Sciences, vol. 91, pp. 99-131, 2017.

[34] M. Arjomandi, S. Agostino, M. Mammone, M. Nelson, and T. Zhou, "Classification of unmanned aerial vehicles," Mech Eng, vol. 3016, 2006.

[35] L. Brooke-Holland, "Unmanned Aerial Vehicles (drones): an introduction," UK House of Commons Library Report, Standard Note SN06493 (25 April 2013), 2012.

[36] R. Weibel and R. J. Hansman, "Safety considerations for operation of different classes of UAVs in the NAS," in AIAA 4th Aviation Technology, Integration and Operations (ATIO) Forum, 2004, p. 6244.

[37] I. Colomina and P. Molina, "Unmanned aerial systems for photogrammetry and remote sensing: A review," ISPRS Journal of Photogrammetry and Remote Sensing, vol. 92, pp. 79-97, 2014.

[38] J. William, "BEST LIST OF TOP 26 DRONE WITH CAMERA FOR 2018," in Drones Globe vol. 2018, ed, 2018.

[39] E. Torun, "UAV Requirements and design consideration," Turkish Land Forces Command Ankara (Turkey)2000.

[40] C. Soutis, "Fibre-reinforced composites in aircraft construction," Progress in Aerospace Sciences, vol. 41, pp. 143-151, 2005.

[41] H. Eisenbeiss, "A mini unmanned aerial vehicle (UAV): system overview and image acquisition," International Archives of Photogrammetry. Remote Sensing and Spatial Information Sciences, vol. 36, pp. $1-7,2004$.

[42] H. Xiang and L. Tian, "Development of a low-cost agricultural remote sensing system based on an autonomous unmanned aerial vehicle (UAV)," Biosystems Engineering, vol. 108, pp. 174-190, 2011.

[43] J. A. Berni, P. J. Zarco-Tejada, L. Suárez, and E. Fereres, "Thermal and narrowband multispectral remote sensing for vegetation monitoring from an unmanned aerial vehicle," IEEE Transactions on Geoscience and Remote Sensing, vol. 47, pp. 722-738, 2009. 
[44] C. M. Gevaert, J. Suomalainen, J. Tang, and L. Kooistra, "Generation of spectral-temporal response surfaces by combining multispectral satellite and hyperspectral UAV imagery for precision agriculture applications," IEEE Journal of Selected Topics in Applied Earth Observations and Remote Sensing, vol. 8, pp. 3140-3146, 2015.

[45] J. Yue, T. Lei, C. Li, and J. Zhu, "The application of unmanned aerial vehicle remote sensing in quickly monitoring crop pests," Intelligent Automation \& Soft Computing, vol. 18, pp. 1043-1052, 2012.

[46] M. C. Quilter and V. J. Anderson, "A proposed method for determining shrub utilization using (LA/LS) imagery," Journal of Range Management, pp. 378-381, 2001.

[47] G. Tomlins and Y. Lee, "Remotely Piloted Aircraft-An Inexpensive Option for Large-Scale Aerial Photography in Forestry Applications," Canadian journal of remote sensing, vol. 9, pp. 76-85, 1983.

[48] T. K. Alexandridis, G. C. Zalidis, and N. G. Silleos, "Mapping irrigated area in Mediterranean basins using low-cost satellite Earth Observation," computers and electronics in agriculture, vol. 64, pp. 93-103, 2008.

[49] T. W. Biggs, P. Thenkabail, M. K. Gumma, C. Scott, G. Parthasaradhi, and H. Turral, "Irrigated area mapping in heterogeneous landscapes with MODIS time series, ground truth and census data, Krishna Basin, India," International Journal of Remote Sensing, vol. 27, pp. 4245-4266, 2006.

[50] V. Dheeravath, P. Thenkabail, G. Chandrakantha, P. Noojipady, G. Reddy, C. M. Biradar, et al., "Irrigated areas of India derived using MODIS $500 \mathrm{~m}$ time series for the years 2001-2003," ISPRS Journal of Photogrammetry and Remote Sensing, vol. 65, pp. 42-59, 2010.

[51] N. Toomanian, A. Gieske, and M. Akbary, "Irrigated area determination by NOAA-Landsat upscaling techniques, Zayandeh River Basin, Isfahan, Iran," International journal of remote sensing, vol. 25, pp. 4945-4960, 2004.

[52] X. Xiao, S. Boles, J. Liu, D. Zhuang, S. Frolking, C. Li, et al., "Mapping paddy rice agriculture in southern China using multi-temporal MODIS images," Remote sensing of environment, vol. 95, pp. 480-492, 2005.

[53] J. R. Irons, J. L. Dwyer, and J. A. Barsi, "The next Landsat satellite: The Landsat data continuity mission," Remote Sensing of Environment, vol. 122, pp. 11-21, 2012.

[54] D. P. Roy, M. Wulder, T. R. Loveland, C. Woodcock, R. Allen, M. Anderson, et al., "Landsat-8: Science and product vision for terrestrial global change research," Remote sensing of Environment, vol. 145, pp. 154$172,2014$.

[55] P. Kingra, R. Setia, J. Kaur, S. Singh, S. P. Singh, S. Kukal, et al., "Assessing the impact of climate variations on wheat yield in north-west India using GIS," Spatial Information Research, pp. 1-14, 2018.

[56] P. Thenkabail, P. GangadharaRao, T. Biggs, M. Krishna, and H. Turral, "Spectral matching techniques to determine historical land-use/land-cover (LULC) and irrigated areas using time-series 0.1-degree AVHRR Pathfinder datasets," Photogrammetric Engineering \& Remote Sensing, vol. 73, pp. 1029-1040, 2007.

[57] M. Burke and D. B. Lobell, "Satellite-based assessment of yield variation and its determinants in smallholder African systems," Proceedings of the National Academy of Sciences, vol. 114, pp. 2189-2194, 2017.

[58] C. Ferencz, P. Bognar, J. Lichtenberger, D. Hamar, G. Tarcsai, G. Timar, et al., "Crop yield estimation by satellite remote sensing," International Journal of Remote Sensing, vol. 25, pp. 4113-4149, 2004.

[59] M. Jain, A. K. Srivastava, R. K. Joon, A. McDonald, K. Royal, M. C. Lisaius, et al., "Mapping smallholder wheat yields and sowing dates using micro-satellite data," Remote Sensing, vol. 8, p. 860, 2016.

[60] J. D. Jang, A. A. Viau, and F. Anctil, "Thermal-water stress index from satellite images," International Journal of Remote Sensing, vol. 27, pp. 1619-1639, 2006.

[61] S. Veysi, A. A. Naseri, S. Hamzeh, and H. Bartholomeus, "A satellite based crop water stress index for irrigation scheduling in sugarcane fields," Agricultural water management, vol. 189, pp. 70-86, 2017.

[62] S.-R. Kim, W.-K. Lee, D.-A. Kwak, G. S. Biging, P. Gong, J.-H. Lee, et al., "Forest cover classification by optimal segmentation of high resolution satellite imagery," Sensors, vol. 11, pp. 1943-1958, 2011.

[63] E. R. Hunt, M. Cavigelli, C. S. Daughtry, J. E. Mcmurtrey, and C. L. Walthall, "Evaluation of digital photography from model aircraft for remote sensing of crop biomass and nitrogen status," Precision Agriculture, vol. 6, pp. 359-378, 2005.

[64] M. E. Bauer and J. E. Cipra, "Identification of agricultural crops by computer processing of ERTS MSS data," 1973.

[65] J. Baluja, M. P. Diago, P. Balda, R. Zorer, F. Meggio, F. Morales, et al., "Assessment of vineyard water status variability by thermal and multispectral imagery using an unmanned aerial vehicle (UAV)," Irrigation Science, vol. 30, pp. 511-522, 2012.

[66] G. Rufino and A. Moccia, "Integrated VIS-NIR hyperspectral/thermal-IR electro-optical payload system for a mini-UAV," in Infotech@ Aerospace, ed, 2005, p. 7009.

[67] S. Ward, J. Hensler, B. Alsalam, and L. F. Gonzalez, "Autonomous UAVs wildlife detection using thermal imaging, predictive navigation and computer vision," in Proceedings of the 2016 IEEE Aerospace Conference, 2016, pp. 1-8. 
[68] A. Callam, "Drone wars: Armed unmanned aerial vehicles," International Affairs Review, vol. 18, 2015.

[69] Drone Warfare [Online]. Available: https://www.thebureauinvestigates.com/projects/drone-war

[70] T. Parmar, "Drones in India," ed: Centre for the study of the drone, 2014.

[71] D. Floreano and R. J. Wood, "Science, technology and the future of small autonomous drones," Nature, vol. 521, p. 460, 2015.

[72] H. González-Jorge, J. Martínez-Sánchez, and M. Bueno, "Unmanned aerial systems for civil applications: A review," Drones, vol. 1, p. 2, 2017.

[73] A. TIBURCA, "AI and the future of drones," in TnW vol. 2018, ed, 2018.

[74] J. Vincent, "Drones taught to spot violent behavior in crowds using AI," in The Verge vol. 2018, ed, 2018.

[75] A. Cavoukian, Privacy and drones: Unmanned aerial vehicles: Information and Privacy Commissioner of Ontario, Canada Ontario, 2012.

[76] B. Rao, A. G. Gopi, and R. Maione, "The societal impact of commercial drones," Technology in Society, vol. 45, pp. 83-90, 2016.

[77] R. Clarke and L. B. Moses, "The regulation of civilian drones' impacts on public safety," Computer Law \& Security Review, vol. 30, pp. 263-285, 2014.

[78] C. Stöcker, R. Bennett, F. Nex, M. Gerke, and J. Zevenbergen, "Review of the current state of UAV regulations," Remote sensing, vol. 9, p. 459, 2017.

[79] T. L. L. o. Congress, "Regulation of Drones," Global Legal Research Center2016.

[80] W. C. B. Nijjar, "DRONE REVOLUTION: REGULATION \& MANAGEMENT."

[81] R. P. Rajagopalan and R. Krishna, "Drones: Guidelines, regulations, and policy gaps in India," Occasional Papers, 2018.

Author Contributions: Gaurav Singhal wrote the classification and application part. Dr. Lini Mathew gave her contribution in the software and hardware design challenges. Dr. Babankumar Bansod wrote and analyzed the introduction and challenges part of this manuscript. 